\title{
Epidemiological Profile of Larynx Cancer at a Tertiary Care Center in Faridkot, Punjab, India
}

\author{
${ }^{1}$ Nitin Arora, ${ }^{2}$ Jyoti Singh, ${ }^{3}$ Jai L Davessar
}

\begin{abstract}
Introduction: Head and neck cancer constitutes about 5 to $50 \%$ among all the cancers found in the world. In India, head and neck cancer constitutes about $30 \%$ of all the cancers, and laryngeal cancer is the second among all head and neck cancers. A high percentage of laryngeal cancers have been linked to tobacco and alcohol use. Smoking is considered as a major risk factor for laryngeal carcinoma, with alcohol use having synergistic effect. The purpose of our study is to highlight the incidence according to age and sex, site of distribution, risk factors involved, and clinical stage at presentation of the laryngeal cancer.
\end{abstract}

Materials and methods: It is a cross-sectional study conducted from January 2014 to November 2014. Patients in the age group 21 to 70 years, of either gender, with a histologically proven malignancy of larynx presenting to the ear, nose, and throat (ENT) outpatient department were enrolled in the study. Patients were observed for age and sex distribution, tumor staging, location and metastasis, commonly associated risk factors, and most common site involved by the disease.

Results: Laryngeal cancers are seen more commonly in males than females. It is seen most commonly in the age group of 51 to 60 years. Supraglottis is the commonest site involved. Synergistic history of smoking and alcohol intake was the most significant risk factor associated. T1 and T2 is the most common primary T stage. Neck metastasis occurs most commonly at N2 stage. The most commonly involved lymph node level is level 2.

Conclusion: We conclude that laryngeal cancers most commonly involve supraglottic region, present at advanced age with synergistic smoking and alcohol intake being the most common risk factor involved, and mostly presents with advanced neck metastasis due to late case presentation, subsequently decreasing the 5 -year survival rate by about $50 \%$. Hence, there is a great need to create awareness about the signs and symptoms of laryngeal cancers, especially among local doctors practicing in villages so that the patients can be referred to a qualified ENT doctor as soon as possible.

Keywords: Early referral, Larynx cancer, Risk factors.

${ }^{1}$ Senior Resident, ${ }^{2}$ Postgraduate Student (2nd Year), ${ }^{3}$ Professor and Head

${ }^{1-3}$ Department of ENT, Guru Gobind Singh Medical College \& Hospital, Faridkot, Punjab, India

Corresponding Author: Nitin Arora, Senior Resident Department of ENT, Guru Gobind Singh Medical College \& Hospital, Faridkot, Punjab, India, Phone: +918427646364 e-mail: drnitinarora89@gmail.com
How to cite this article: Arora N, Singh J, Davessar JL. Epidemiological Profile of Larynx Cancer at a Tertiary Care Center in Faridkot, Punjab, India. Int J Phonosurg Laryngol 2017;7(2):48-51.

\section{Source of support: Nil}

\section{Conflict of interest: None}

\section{INTRODUCTION}

Head and neck cancer constitutes about 5 to $50 \%$ among all the cancers found in the world. ${ }^{1}$ In India, head and neck cancer constitutes about $30 \%$ of all the cancers, and laryngeal cancer is the second among all head and neck cancers. $^{2}$

A high percentage of laryngeal cancers have been linked to tobacco and alcohol use. Smoking is considered as a major risk factor for laryngeal carcinoma, with alcohol use having synergistic effect. ${ }^{3}$

Histopathologically, about 95 to $98 \%$ laryngeal cancers are of squamous cell origin. ${ }^{4}$ The disease is more commonly seen in the males than females with highest incidence occurring between the fifth and seventh decade of life. ${ }^{5}$

The purpose of our study was to highlight the incidence according to age and sex, site of distribution, frequency of risk factors involved, and clinical stage at presentation of the laryngeal cancer.

\section{MATERIALS AND METHODS}

Patients with histologically proven squamous cell carcinoma of the larynx (all the three subsites) were chosen from patients presenting to the Department of Otorhinolaryngology, Guru Gobind Singh Medical College \& Hospital, Faridkot, Punjab, India, during the period of January 2014 to November 2014.

This is a cross-sectional study done in a period from January 2014 to November 2014, in which a total of 100 patients diagnosed with laryngeal cancer during this period were enrolled for the study and were observed for the age and sex distribution, tumor staging, location, metastasis, most common risk factors associated with laryngeal cancer, and most common site involved in the larynx.

\section{Inclusion Criteria}

- Age group 21 to 70 years, as patients below 21 will have least chance of having larynx cancer and patients 
above 70 might not be in good condition to cooperate for study.

- Primary confined to larynx

- Histopathologically proven malignancy.

\section{Exclusion Criteria}

- Primary not confined to larynx

- Previously irradiated patients

- Previously operated

- Patients without the written consent.

\section{RESULTS}

Laryngeal cancers were more common in males (93\%), than in females $(7 \%)$ (Graph 1). It is most prevalent in age group of 51 to 60 years (45\%), followed by 41 to 50 years ( $25 \%)$, then followed by 61 to 70 years $(24 \%), 31$ to 40 years (4\%), 21 to 30 (2\%) (Graph 2). Supraglottis was the most common site $(80 \%)$ followed by glottis $(20 \%)$; none of the patients had primary in subglottis (Graph 3). Synergistic alcohol and smoking was the most significant risk factor

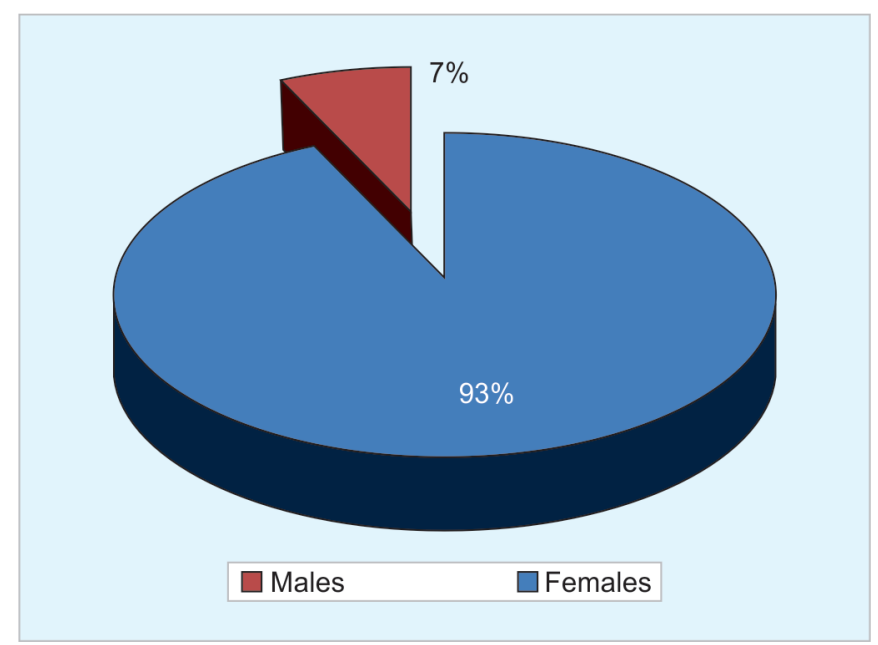

Graph 1: Sex distribution

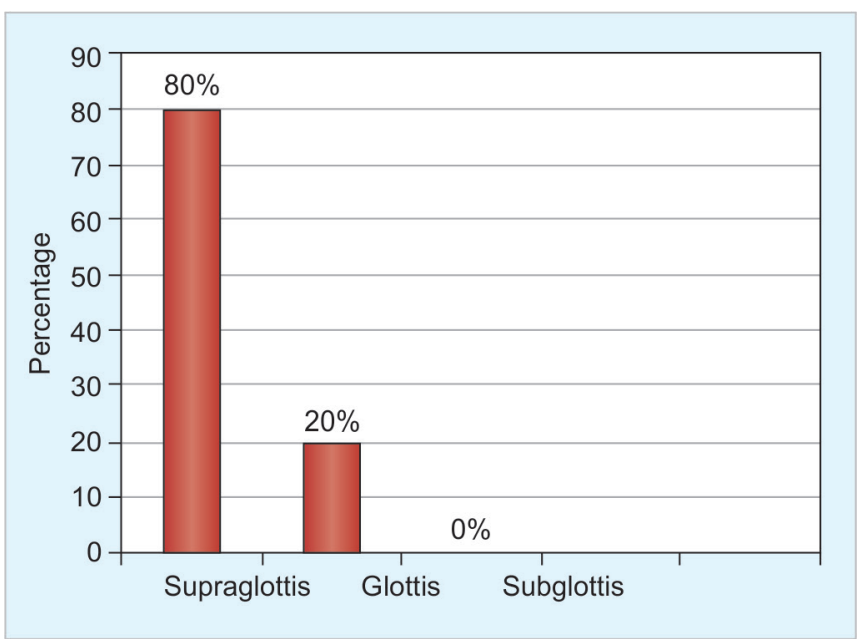

Graph 3: Site distribution present in $97 \%$ patients, while alcohol only was present in $2 \%$ and smoking only in $1 \%$ of patients (Graph 4 ). T1 and $\mathrm{T} 2$ were the most common primary $\mathrm{T}$ stage involved (28\%), each followed by T3 (26\%) and T4 (18\%) (Graph 5). Neck metastasis occurred most commonly at level 2 $(50 \%)$ followed by level $1(20 \%)$, level $3(14 \%)$, and level 4 (5\%) (Graph 6). N2 stage was most common stage of presentation $(67 \%)$ followed by N1 (20\%), N0 (11\%), and N3 (2\%) (Graph 7).

\section{DISCUSSION}

Head and neck cancer constitutes about 5 to $50 \%$ among all the cancers found in the world. ${ }^{1}$ In India, head and neck cancer constitutes about $30 \%$ of all cancers, and laryngeal cancer is second among all head and neck cancers. $^{2}$

A high percentage of laryngeal cancers have been linked to tobacco and alcohol use. Smoking is considered as a major risk factor for laryngeal carcinoma, with alcohol use having synergistic effect. ${ }^{3}$

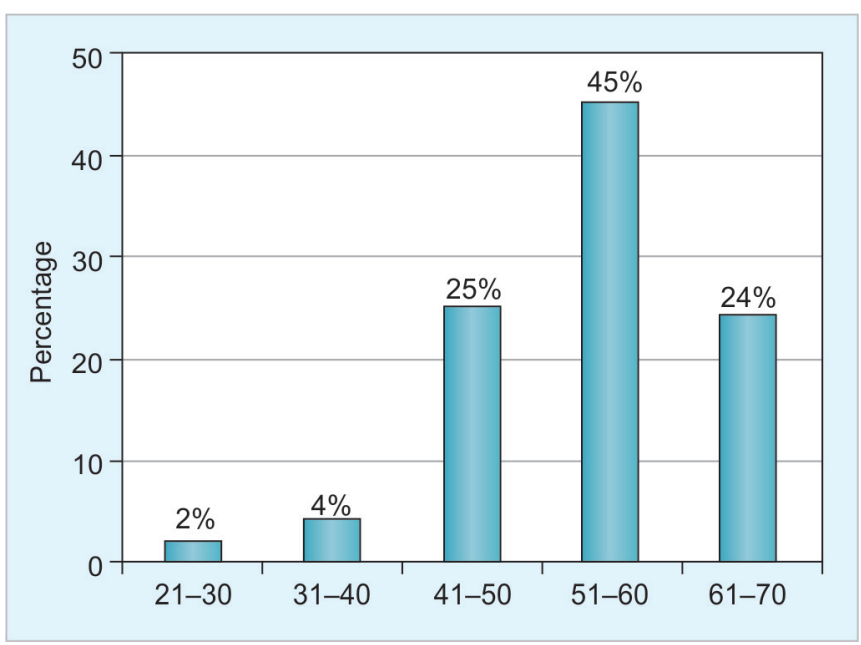

Graph 2: Age distribution

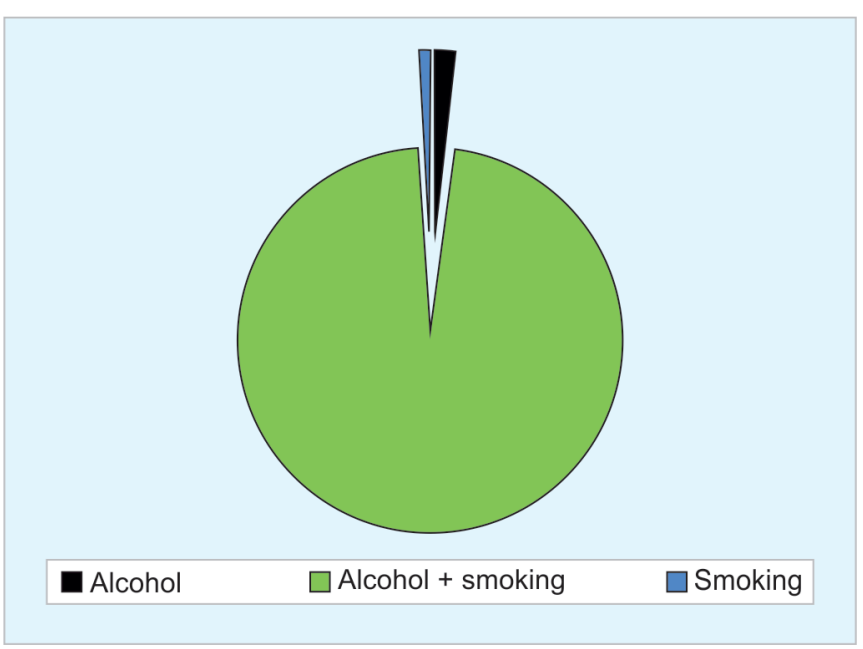

Graph 4: Risk factors 


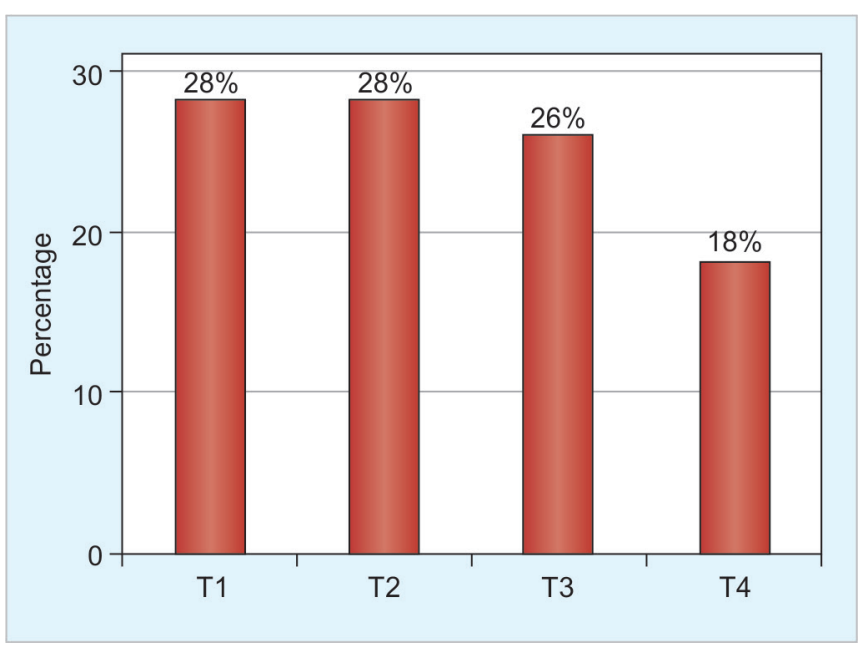

Graph 5: T stage of primary tumor

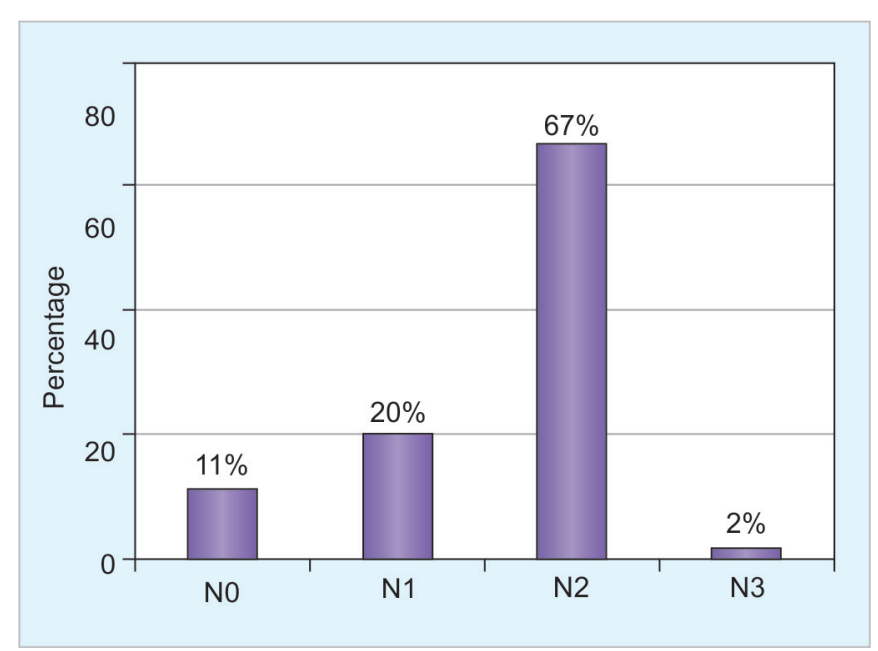

Graph 7: Distribution of N stage

Histopathologically, about 95 to $98 \%$ of laryngeal cancers are of squamous cell origin. ${ }^{4}$ The disease is much more common in the males. The maximum incidence of laryngeal cancer occurs between the fifth and seventh decade of life. ${ }^{5}$

Due to high prevalence of laryngeal cancer in Faridkot, Punjab, large number of cases of laryngeal cancer are seen in our institute. This study was undertaken in the Department of Otorhinolaryngology, at Guru Gobind Singh Medical College \& Hospital, Faridkot, Punjab, India, to determine epidemiologic profile of laryngeal cancer, its incidence according to age and sex, site distribution, frequency of risk factors involved, and clinical stage at presentation.

This study was carried out on 100 patients. The age group most commonly seen in our study was of 51 to 60 years (45\%) followed by 41 to 50 years $(25 \%)$, then followed by 61 to 70 years (24\%). Our results match with those of Mehrotra et $\mathrm{al}^{6}$ and Larizadeh et $\mathrm{al}^{7}$

In our study, $81 \%$ of patients were males and 19\% were females. These results were slightly different from

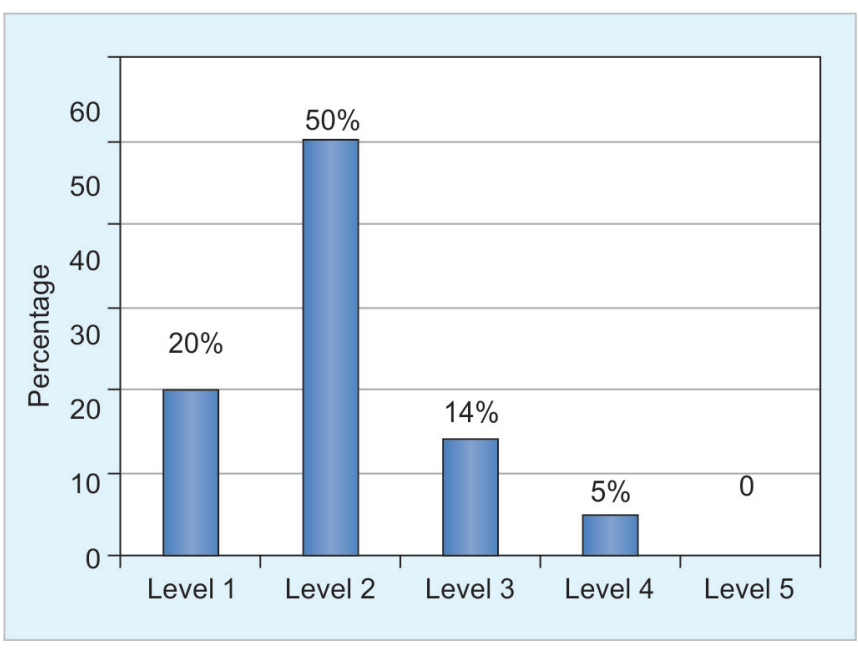

Graph 6: Levels of metastasis

study conducted by Larizadeh et al. ${ }^{7}$ They observed 73\% patients were males and $27 \%$ were females. Similarly, Bhattacharjee et $\mathrm{al}^{8}$ in their study observed male constituted $74 \%$ of all the patients, while females constituted $26 \%$ of all the patients. This signifies that males were more exposed to the risk factors.

In our study, male to female ratio was $4: 1$, which is lower than those reported by Shaw ${ }^{9}$ (11:1) and same as Iwamoto $^{10}(4: 1)$ in their studies.

Supraglottic cancer was found in $80 \%$ cases, while glottic cancer was found in $20 \%$ cases. In a study conducted by Akmansu et $\mathrm{al}^{11}{ }^{11}$ tumor localization was as follows: $26.5 \%$ glottis and $66.7 \%$ in supraglottis.

In our study, commonly seen primary stage of presentation is $\mathrm{T} 1$ and $\mathrm{T} 2$ stage ( $28 \%)$, followed by T3 (26\%) and T4 (18\%).

In our study, the most common $\mathrm{N}$ stage was $\mathrm{N} 2$ stage $(67 \%)$, followed by N1 (20\%), N0 (11\%), and N3 (2\%), which is different from the study conducted by Li et al, ${ }^{12}$ who found that nodal metastasis was most common at early stage of $\mathrm{N} 1$, while the most common level involvement was seen at level 2.

\section{CONCLUSION}

We conclude that the laryngeal cancer most commonly involves supraglottic region, presents at advanced age, with synergistic smoking and alcohol intake being the most common risk factor involved, and mostly presents with advanced neck metastasis due to late case presentation, subsequently decreasing the 5-year survival rate by about $50 \%$. Hence, there is a great need to create awareness about the signs and symptoms of laryngeal cancers, especially among local doctors practicing in villages so that the patients can be referred to a qualified ENT doctor as soon as possible. 


\section{REFERENCES}

1. Garfinkel L. Perspective on cancer prevention. Cancer J Clin 1995 Jan-Feb;45(1):5-7.

2. Chu EA, Kim YJ. Laryngeal cancer: diagnosis and preoperative work-up. Otolaryngol Clin North Am 2008 Aug;41(4):673-695.

3. Sadri M, McMahon J, Parker A. Laryngeal dysplasia: etiology and molecular biology. J Laryngol Otol 2006 Mar;120(3): 170-177.

4. Ballenger JJ, Snow JB. Otorhinolaryngology: head and neck surgery. 15th ed. Philadelphia (PA): Williams \& Wilkins; 1996.

5. Cattaruzza MS, Maisonneuve P, Boyle P. Epidemiology of laryngeal cancer. Eur J Cancer B Oral Oncol 1996 Sep; 32B(5):293-305.

6. Mehrotra R, Singh M, Gupta RK, Singh M, Kapoor AK. Trends of prevalence and pathological spectrum of head and neck cancers in North India. Indian J Cancer 2005 Apr-Jun;42(2): 89-93.
7. Larizadeh MH, Damghani MA, Shabani M. Epidemiological characteristics of head and neck cancers in Southeast of Iran. Iran J Cancer Prev 2014 Spring;7(2):80-86.

8. Bhattacharjee A, Chakraborty A, Purkaystha P. Prevalence of head and neck cancers in the north east-an institutional study. Indian J Otolaryngol Head Neck Surg 2006 Jan;58(1):15-19.

9. Shaw HJ. Glottic cancer of larynx. J Laryngol Otol 1965 Jan;79: $1-14$.

10. Iwamoto $H$. An epidemiological study of laryngeal cancer in Japan. Laryngoscope 1975 Jul;85(7):1162-1172.

11. Akmansu SH, Korkmaz H, Dursun E, Erbek SS, Gocmen H, Unal T, Ozeri C. Clinical and histopathological indicators of neck metastasis in laryngeal carcinoma. Tr J Med Sci 1999;29:313-317.

12. Li XM, Wei WI, Guo XF, Yuen PW, Lam LK. Cervical lymph node metastatic patterns of squamous carcinomas in the upper aero digestive tract. J Laryngol Otol 1996 Oct;110(10):937-941. 